EGTRIB Journal

JOURNAL OF

THE EGYPTIAN SOCIETY OF TRIBOLOGY

VOLUME 18, No. 1, January 2021, pp. 18 - 28 ISSN 2090 - 5882

(Received September 11. 2020, Accepted in final form October 15. $2020 \quad \underline{\text { www.egtribjournal.com }}$

\title{
TRIBOLOGICAL PROPERTIES OF POLYESTER COMPOSITES FILLED BY RECYCLED THERMOPLASTIC POLYMERS
}

\author{
Bakry M. ${ }^{1}$, Ameer A. K. ${ }^{2}$ and Badran A. H. ${ }^{2}$ \\ ${ }^{1}$ Department of Engineering Materials and Design, Faculty of Energy Engineering, Aswan University, \\ Aswan, 81528, EGYPT. \\ ${ }^{2}$ Department of Production Engineering and Mechanical Design, Faculty of Engineering, Minia University, \\ El-Minia, EGYPT.
}

\begin{abstract}
Environmental consciousness today stimulates the researchers worldwide on the studies of recycling polymer wastes to be applied as reinforcement in polymer composites. In this study, polymer composites were prepared by filling thermosetting matrix (polyester) with different types and contents of thermoplastic recycled polymers. Paraffin oil as lubricant was added to the composites before molding. The recycled thermoplastic polymers were polyethylene (PE), polypropylene (PP) and polytetrafluoroethylene (PTFE). Pin-on-Disc wear testing machine was designed and fabricated to determine friction and wear.

It was found that composites filled with oil showed relatively low friction coefficient and wear. The addition of recycled thermoplastics to polyester matrix had a significant effect on the tribological properties of the composites. It was observed that filler content greatly affected the friction and wear behavior of polyester resins polymer under dry sliding conditions. Polyester composites filled by $2.0 \mathrm{wt}$. \% PTFE displayed the lowest values of friction coefficient, while composites containing 5.0 wt. \% PTEF showed the lowest wear. Based on that, it is recommended to apply test specimens filled by $4.0 \mathrm{wt}$. \% oil and 5.0 wt. \% PTFE in bearing applications.
\end{abstract}

\section{KEYWORDS}

Friction coefficient, wear, polyester resin, recycled thermoplastic polymers.

\section{INTRODUCTION}

Waste management is a relatively recent phenomenon in our developing countries. There is a general accord that disposes of different plastic waste in the workshops is a top priority. Recycling targets for some plastic waste types are important measures to improve the plastic waste management system, $[1,2]$. The recycling rate should increase and it must be considered necessary to increase the security of the plastic waste supply. With the remark that plastic waste generation and management have broad field, [3, 4]. Besides, plastic can act on many different purposes so that the use of plastics is growing globally at an annual growth rate of $3.7 \%$. Environmental problems related to plastic 
wastes include the resources lack, hazardous substances in plastics and bad waste management $[4,5]$.

The scrap must be treated and thereafter being used as filler for the polymer composites. This occurrence will be an important issue in the future, since the amount of waste will increase dramatically, [6,7]. The usage of polymeric composite is being widely applied in bearing and guide ways manufacturing, [8]. In extreme working conditions, it is required to develop the self-lubricating polymeric surfaces. Polyamide (PA12) filled by vegetables oils such in content up to $10 \mathrm{wt}$. \%, were investigated, [9, 10]. It was observed that, friction coefficient decreased with increasing oil content. The minimum value of friction coefficient was observed for flax seed oil. Recently, PE and PA12 were reinforced by graphene nanoplatelets (GNPs) and paraffin oil. Friction and wear of the suggested composites were tested, [12 - 13]. It was found that the proposed composites had lower coefficient of friction and wear than those of the unfilled PE and PA6. Several attempts were carried out to develop the tribological properties of bearing composites, [14 - 23]. Those attempts depended on enhancing the mechanical and tribological properties of polyester by filling by thermoplastic polymers of relatively better performance.

The main objective of this work is to fabricate a composite material used as journal bearing from the workshops polymer wastes. Besides, it aims to investigate the tribological properties of the prepared composites to determine the optimum composition and optimum properties.

\section{EXPREMENTAL WORK}

Materials

Thermoplastics polyethylene (PE), polypropylene (PP) and polytetrafluoroethylene (PTFE) were obtained from workshop wastes of Faculty of Energy engineering, Aswan University, Egypt.

Composite preparation

The granulates of the recycled polymers were screened to get the fine particles (less than $300 \mu \mathrm{m})$. Different contents $(1,2,3,4$, and $5 \mathrm{wt}$. \%) from thermoplastic polymers and paraffin oil (lubricant material) were added to polyester resins (matrix). Hardener material and polyester are kept at $2: 10$ by weight in the mixture. The mixtures were individually molded in cylindrical mold $8 \mathrm{~mm}$ diameter and $40 \mathrm{~mm}$ length from aluminum foil, Fig. 1. Air-bubbles have been removed during casting process. All specimens were left at room temperature for $24 \mathrm{~h}$ to solidify, Fig. 2 .

Tribological properties

A pin-on-disc test rig was used to investigate the sliding friction and wear characteristics of the tested composites, Fig. 3 at room temperature and the disc used with known roughness of $3.5 \mu \mathrm{m} R_{\mathrm{a}}$. The sliding surface of the disc was rubbed by emery paper to remove the contaminants then washed by acetone and left to dry in air. The applied friction coefficients were recorded at each $30 \mathrm{~s}$. The average of four readings was considered. Furthermore, the wear tests were recorded after $120 \mathrm{~s}$. The applied normal load on the pin specimen was weights varied from 5.0 to $10.0 \mathrm{~N}$. The linear sliding velocity of the pin specimen on the flat surface of the rotating disc is calculated by multiplying the 
angular velocity by the radius of the sliding track. The linear velocity of the friction test was $2.0 \mathrm{~m} / \mathrm{s}$.

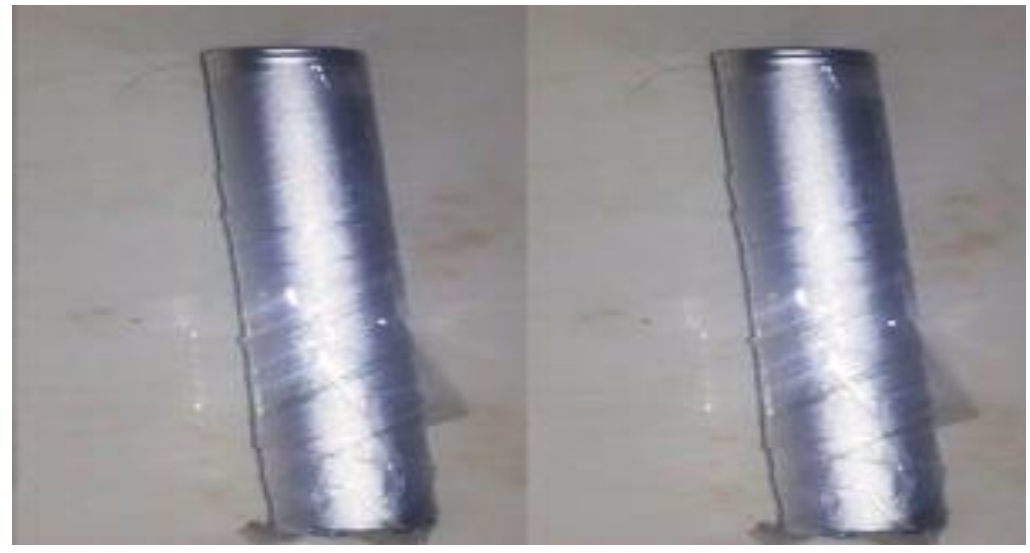

Fig. 1 Aluminum foil mold in cylindrical shape.

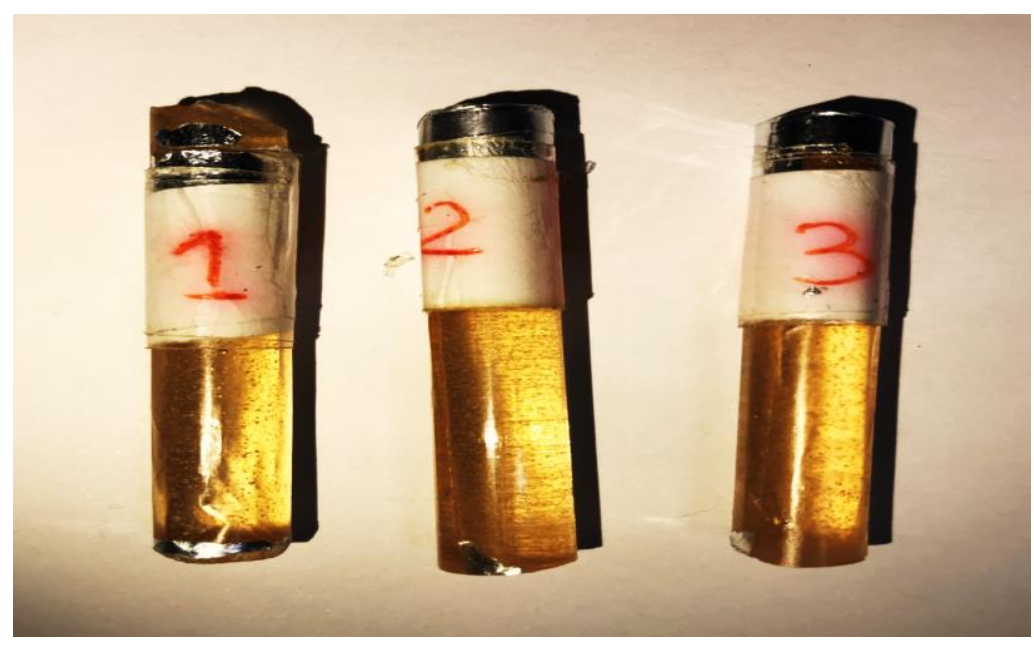

Fig. 2 Test specimens.

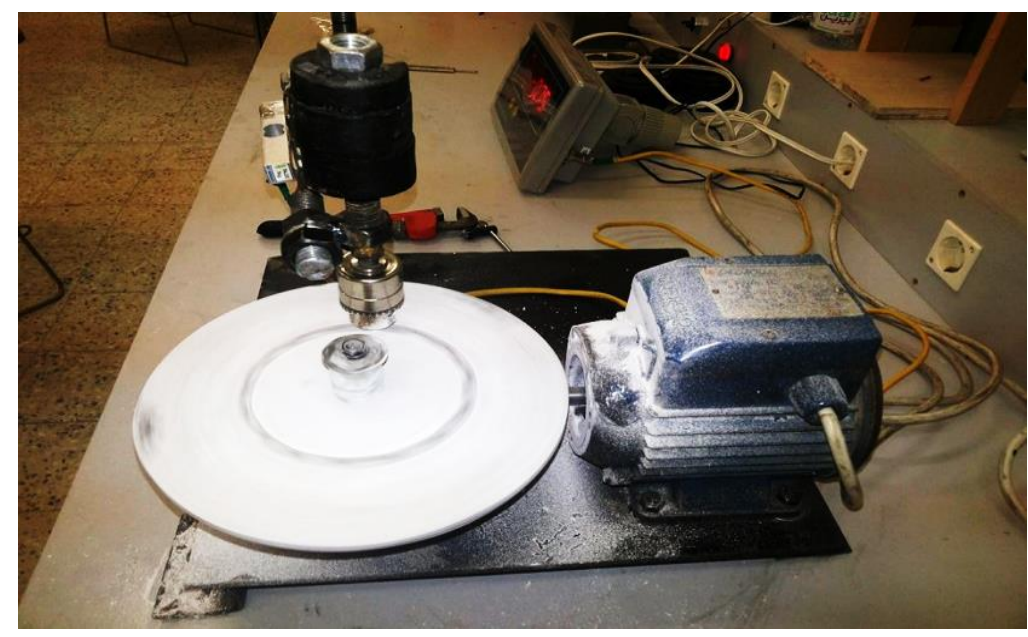

Fig. 3 Pin on disk test rig. 


\section{RESULTS AND DISCUSSION}

Effect of the addition of into the polyester resin

Figure 4 shows the effect of oil on the friction coefficient of polyester resin matrix. It is observed that the specimens containing 3.0 wt. \% oil showed slight increase in friction coefficient. However, the specimens having 4.0 and 5.0 wt. \% indicated comparatively low friction coefficient. In other words, increasing the oil content up to $5.0 \mathrm{wt}$. \% in the composite matrix had significant decrease in the friction. The friction coefficient decrease may be due to the oil stored in the pores of the polyester that fed oil to form film on the sliding surfaces and separated the two contact surfaces. The oil inside the pores leaked to the contact area and caused the friction decrease. Besides, oil film prevented materials transfer into the polymeric pin surface. Figure 5 shows the effect of different contents of paraffin oil on the wear of polyester resin matrix. Wear of the tested specimens decreased as the oil content decreased. The specimens of $4.0 \mathrm{wt}$. \% paraffin oil showed minimum wear rate. Based on that observation, those specimens were filled by different thermoplastics fillers.

Effect of the addition of PP filler into the polyester resin matrix

Figure 6 shows the effect of PP contents on the friction coefficient of the tested composites. As shown, the addition of PP to polyester resin matrix filled by $4 \mathrm{wt}$. \% oil reduced the friction coefficient. However, the sample contained 1.0, 2.0, and 3.0 wt. \% PP showed higher friction coefficient compared to the other composites. The composites filled by 4.0 and $5.0 \mathrm{wt}$. \% showed minimum friction coefficient compared to other composites. The friction coefficient decreased with increasing PP content in specimens. The composites filled by $3.0 \mathrm{wt}$. \% PP displayed the lowest values of wear, Fig. 7. Wear decreased down to minimum then slightly increased with increasing PP content more than $3.0 \mathrm{wt}$. \%. This may be attributed to the weak cohesion between the polyester and PP.

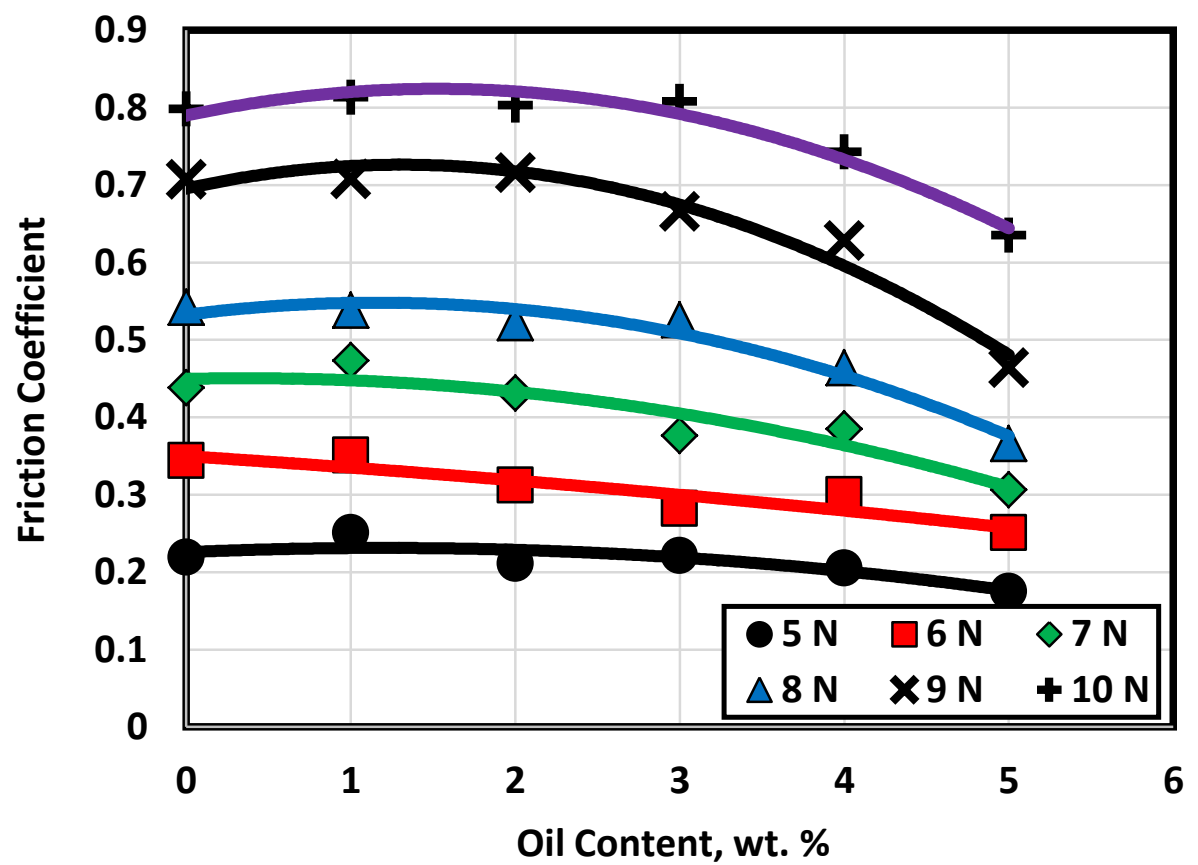

Fig. 4 Effect of the addition of paraffin oil on the friction coefficient of polyester resin. 


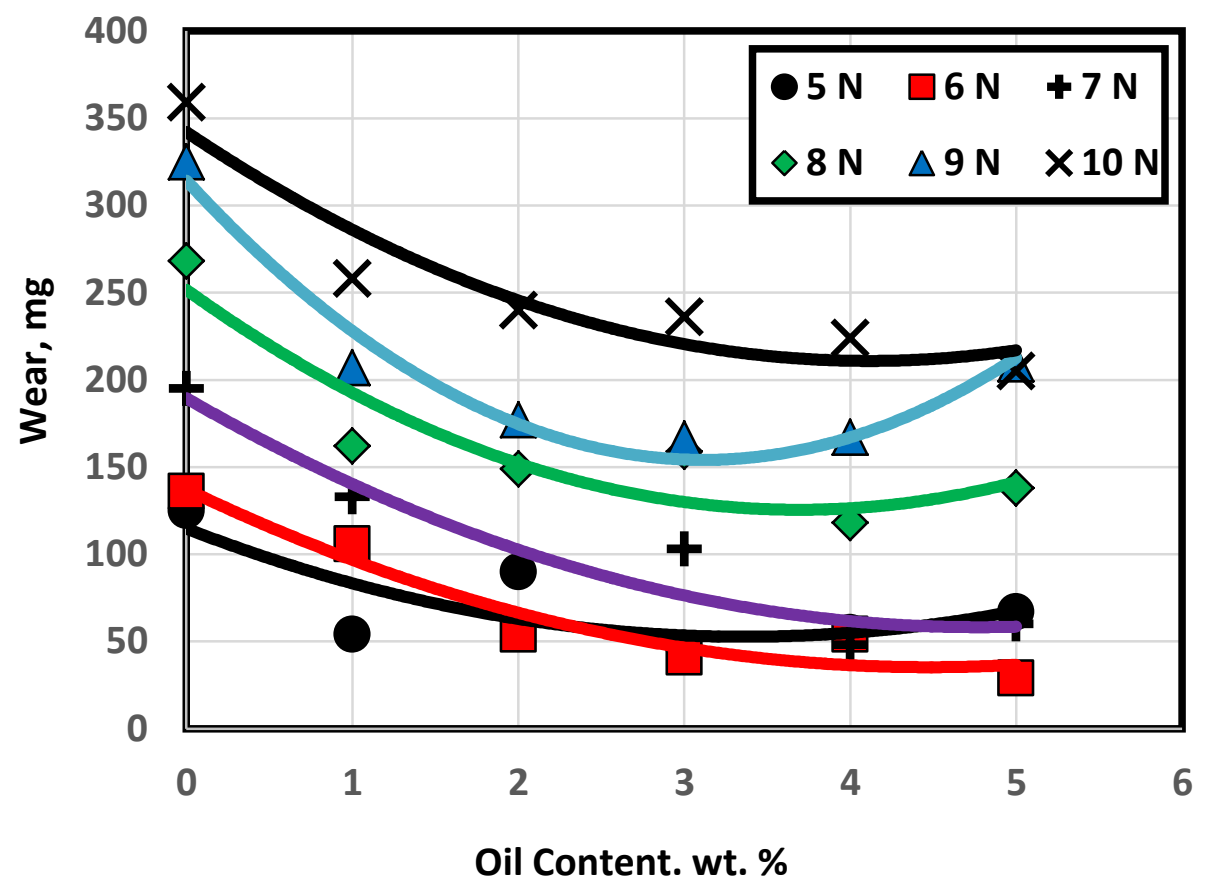

Fig. 5 Effect of the addition of oil on the wear of polyester resin.

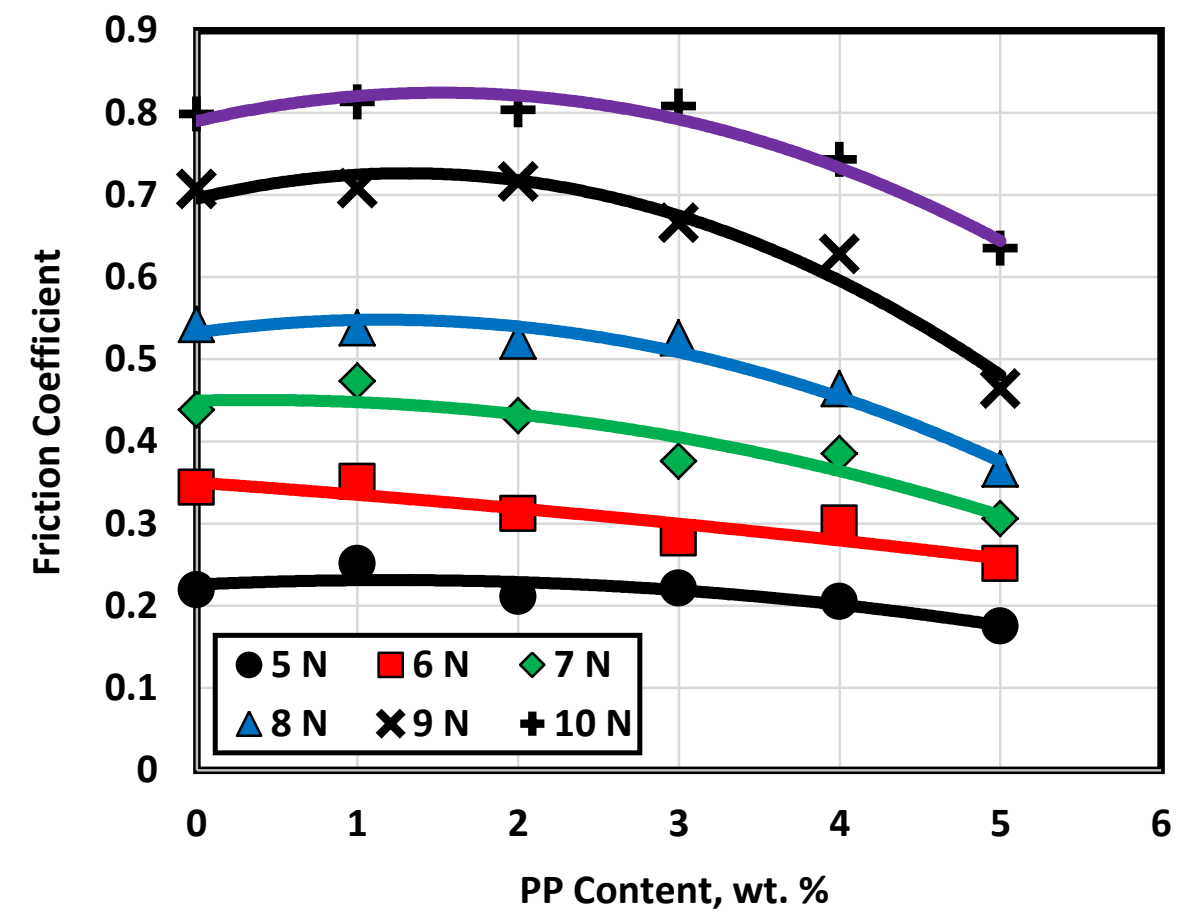

Fig. 6 Effect of the addition of PP on the friction coefficient. 


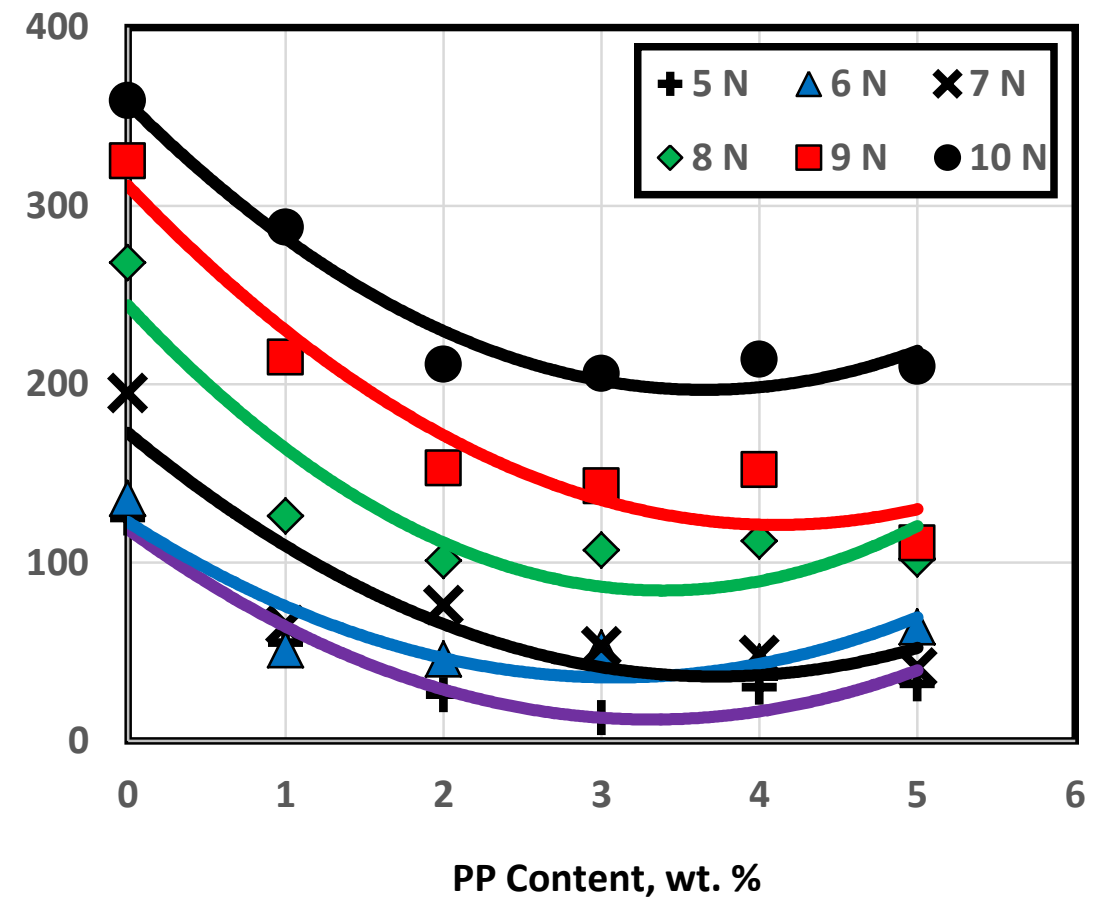

Fig. 7 Effect of the addition of PP on the wear.

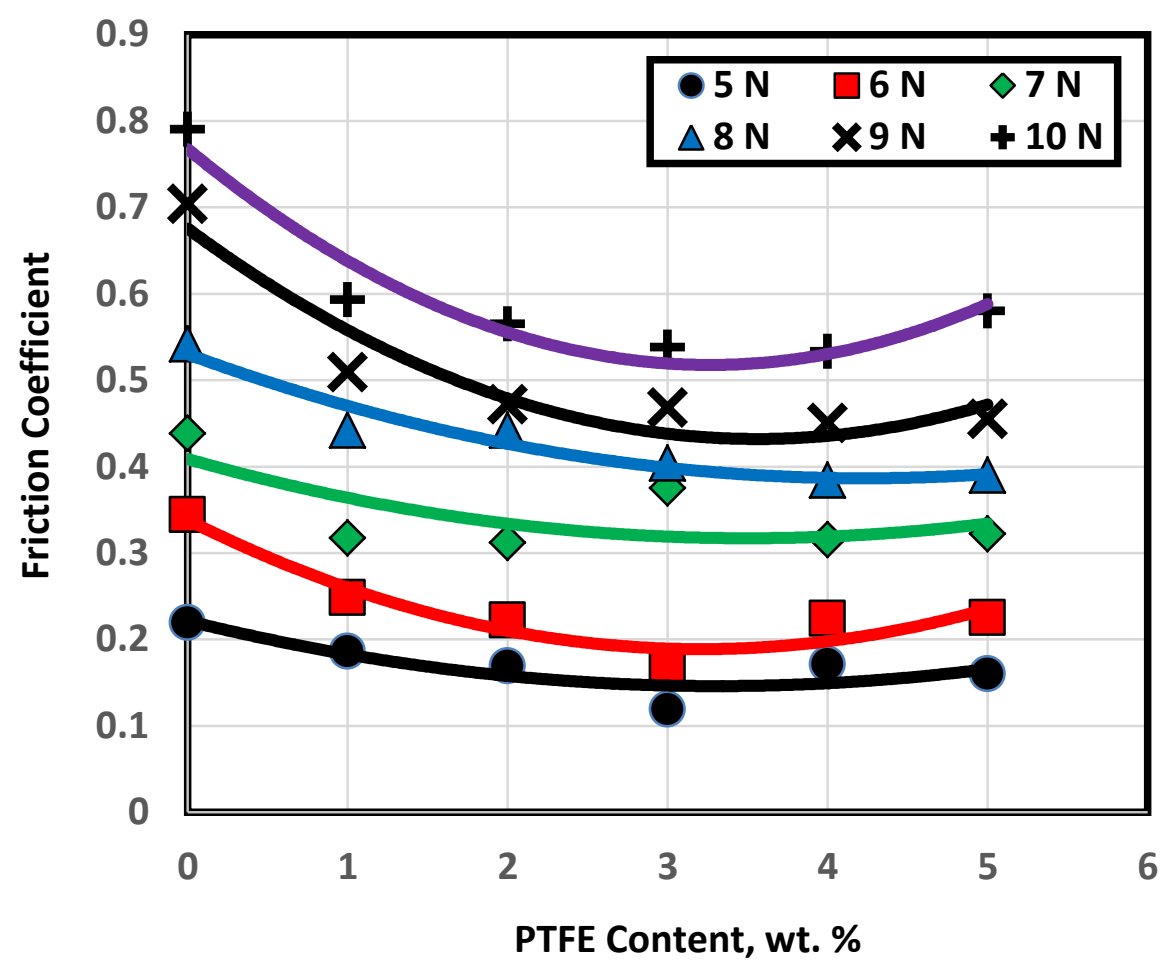

Fig. 8 Effect of the addition of PTEF on the friction coefficient. 


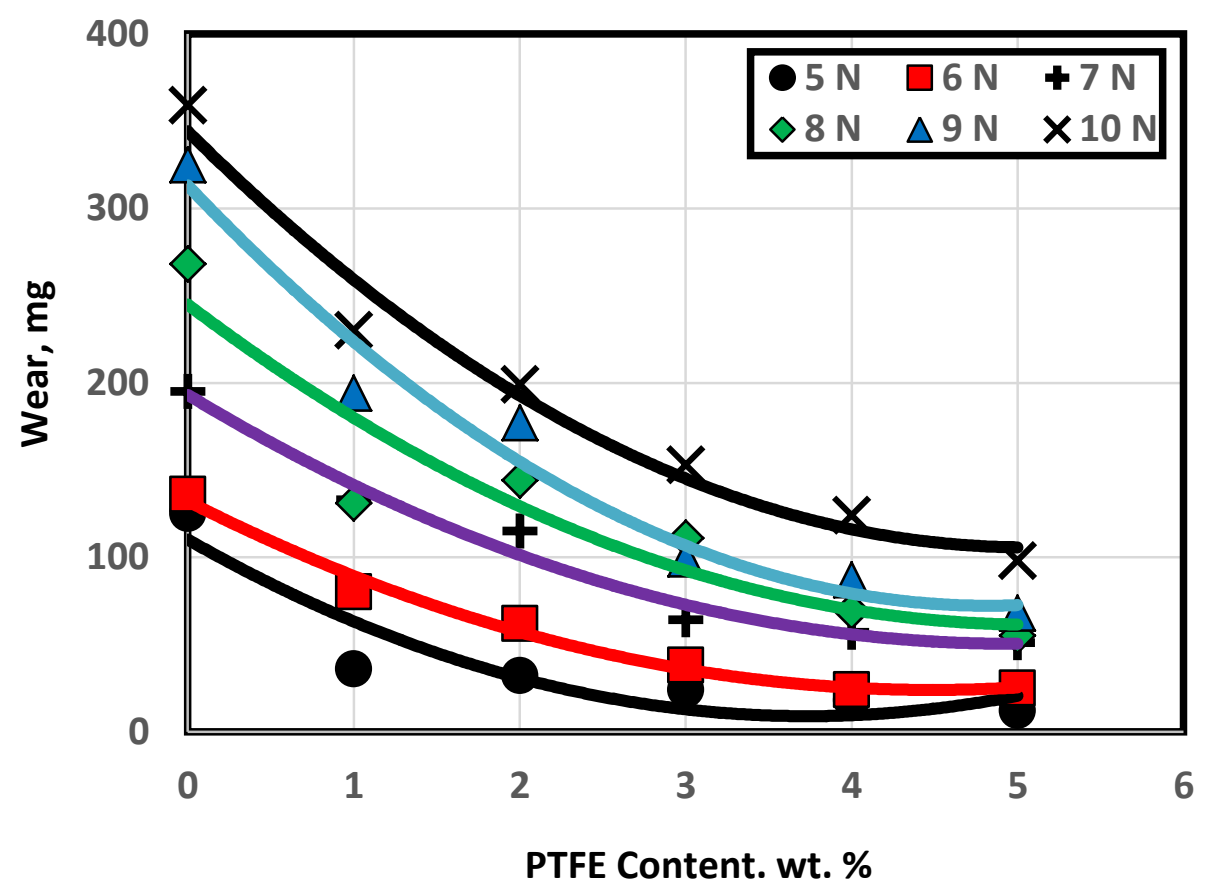

Fig. 9 Effect of the addition of PTEF on the wear.

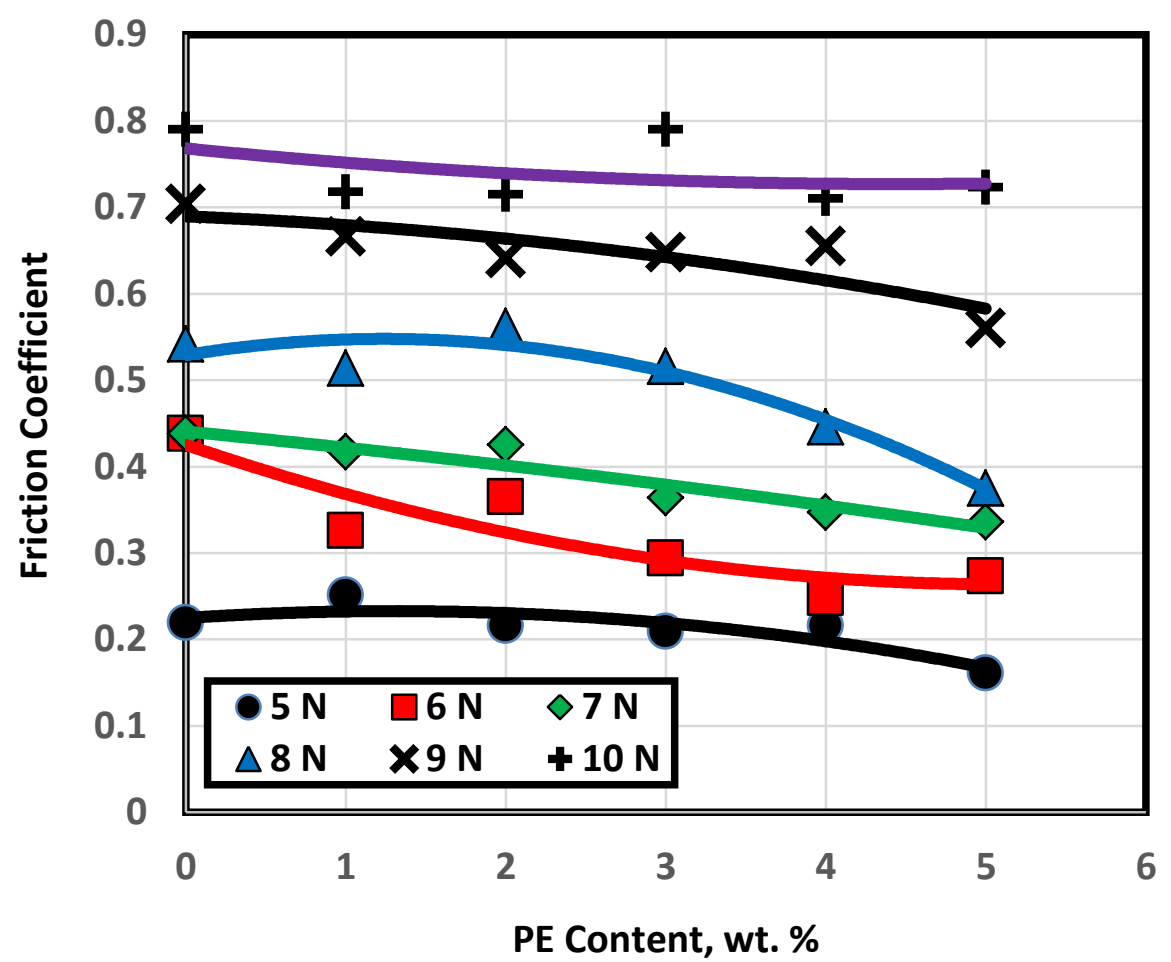

Fig. 10 Effect of the addition of PE on the friction coefficient. 


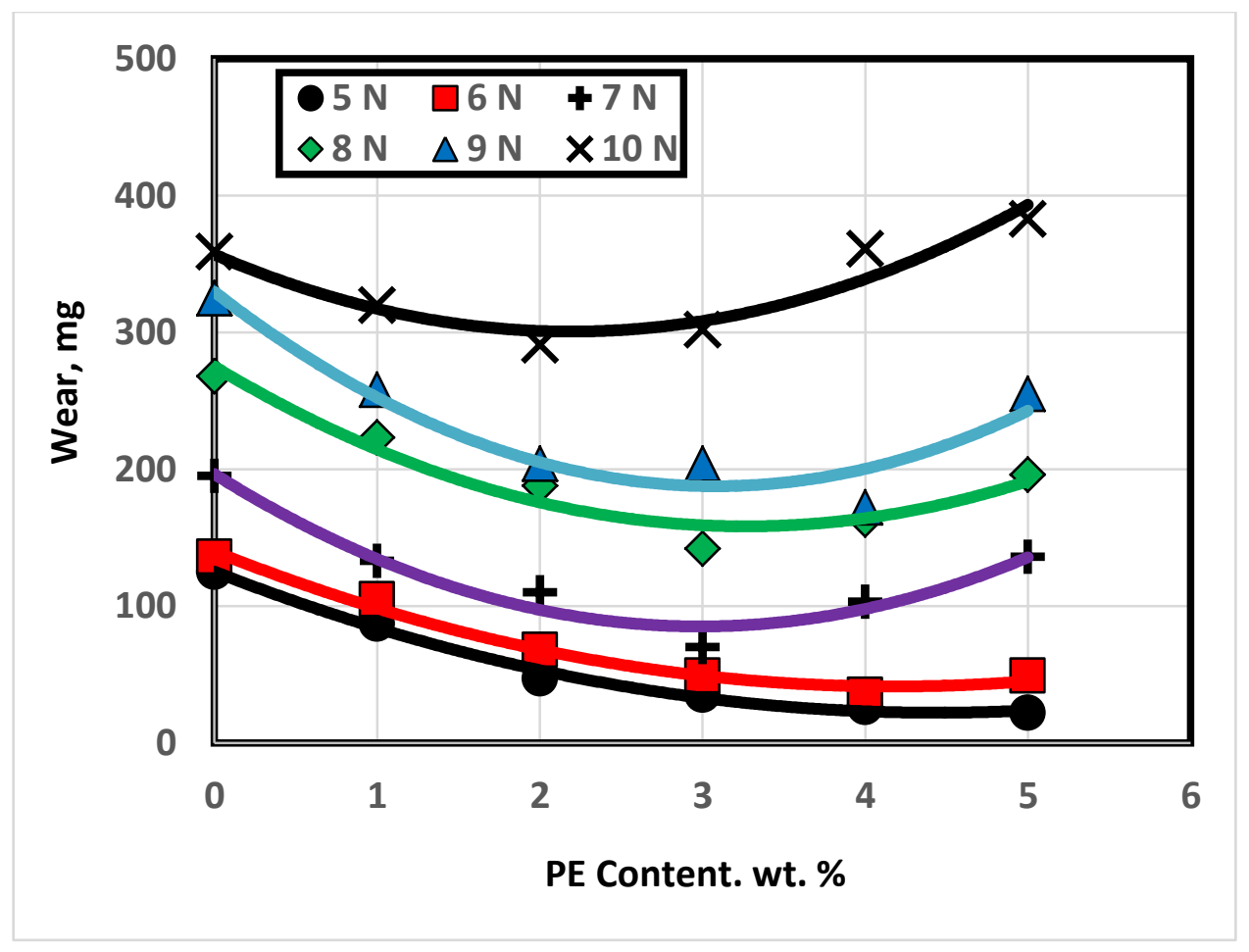

Fig. 11 Effect of the addition of PE on the wear.

Effect of the addition of PTEF filler into the polyester resin matrix

Figure 8 reveals the effect of PTEF filler on the friction coefficient of the tested composite. Friction coefficient decreased down to minimum at $3.0 \mathrm{wt}$. \% PTFE then increased with further increasing PTFE. Wear drastically decreased with increasing PTFE, Fig. 9. The figure confirmed that wear was much influenced by PTFE. This observation can propose those composites in applications.

Effect of the addition of PE filler into the polyester resin matrix

Figure 10 shows the effect of PE filler on the friction coefficient. Friction coefficient showed slight decrease with increasing PE content, where test specimens filled by 5.0 wt. \% PE has shown the lowest friction coefficient. Wear displayed lower values at 3.0 wt. \% at higher loads.

Finally, test specimens that have shown the lowest values of friction coefficient and wear are shown in Figs. 12 and 13, respectively. The specimens filled by 2.0 wt. \% PTFE displayed the lowest values of friction coefficient, Fig. 12. While the specimens containing $5.0 \mathrm{wt}$. \% PTEF showed the lowest wear, Fig. 13. It is recommended to apply test specimens filled by 4.0 wt. \% oil and 5.0 wt. \% PTFE. 


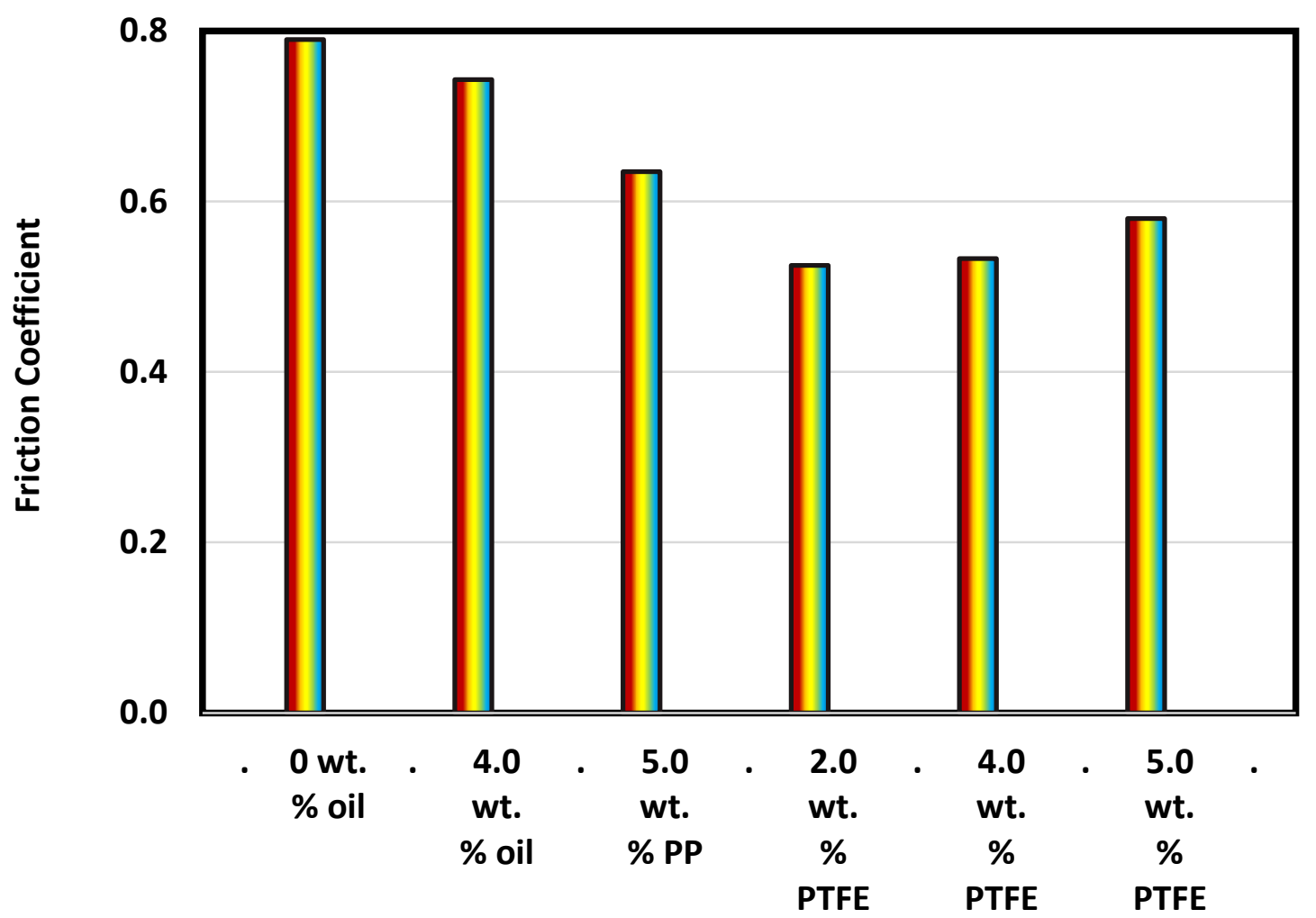

Fig. 12 Best specimens in friction tests.

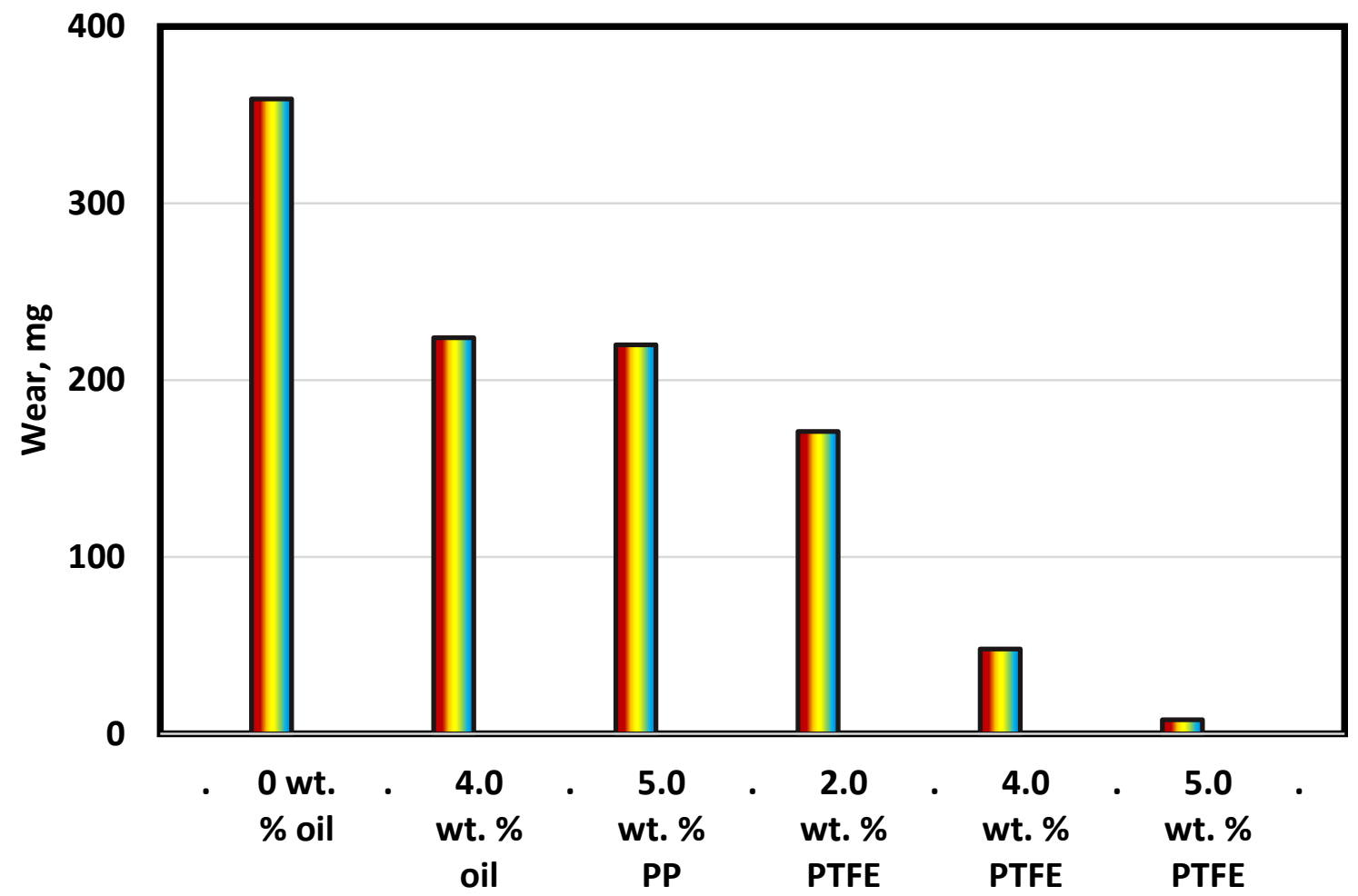

Fig. 13 Best specimens in wear tests. 


\section{CONCLUSIONS}

The present work includes details of extensive study on tribological performance of Thermoplastics particulates filled in polyester resins matrix composites. The followings are the important observations extracted from the study.

1. Polyester resins composites filled by oil and reinforced by polymer particles show relatively low friction coefficients and wear, that recommends these composites for industrial applications such as self-lubricated materials.

2. It was observed that filler content greatly affected the friction and wear behavior of the tested composites.

3. Test specimens filled by $2.0 \mathrm{wt}$. \% PTFE displayed the lowest values of friction coefficient, while the specimens containing 5.0 wt. \% PTEF showed the lowest wear. Based on that, it is recommended to apply test specimens filled by $4.0 \mathrm{wt}$. \% oil and 5.0 wt. \% PTFE.

\section{REFERENCES}

1. Weber R., Gaius C., Tysklind M., Johnston P., Forter M., Hollerti H., et al., "Dioxnand POP- contaminated sites-contemporary and future relevance and challenges: Overview and background, aims and scope of the series", Environmental Science and Pollution Research International, 15, (5), pp. 363 - 393, (2008).

2. Zhang S. W., "State-of-the-art of polymer Tribology", Tribology International, Vol. 31, pp. 49 - 60, (1998).

3. European Commission (EC). White Paper on Climate Change, SEC 2009. pp. 386-388

4. Nzeadibe T. C., Iwuoha H. C., "Informal waste recycling in Lagos", Nigeria, Communications in Waste and Resource Management, 9 (1), pp. 24 - 31, (2008).

5. Plastic Waste Management Institute. An Introduction to Plastic Recycling. Tokyo, Japan: Plastic Waste Management Institute, (2016).

6. Khashaba M. I., Ezzat F. H., and Ali W. Y., " Mechanical and Tribological Properties of Recycled Polymers", Proceedings of The International Conference of Development and Environment, Assiut University, March 26 - 28, Assiut, Egypt, 2002, pp. 381 - 390, (2002).

7. Khashaba M. I., and Ali W. Y., "Mechanical Properties of Epoxy Filled By Recycled Polymeric Powders", Proceedings of The International Conference of Development and Environment, Assiut University, March 26 - 28, Assiut, Egypt, 2002, pp. 373 - 379, (2002). 8. Zare Y., "Recycled Polymers: Properties and Applications", Vol. 2. Rijeka, Croatia: Intech Open; pp. 27 - 50, (2016).

9. Ibrahim A. S., Khashaba M. I. and Ali W. Y., "Comparative Performance of Friction Coefficient Displayed by Polymers Filled by Vegetables Oils", Journal of the Egyptian Society of Tribology, Vol. 12, No. 4, October 2015, pp. 53- 66, (2015).

10. Ibrahim A. S., Khashaba M. I., Ali W. Y., "Friction coefficient displayed by polyamide filled by vegetables oils", Journal of the Egyptian Society of Tribology, Vol. 11, No. 3, July 2014, pp. 34 - 44, (2014).

11. Hassan A. El-Sayed M., EiD A. I., El-Sheikh M., Ali W. Y., "Tribological Properties of Low Density Polyethylene and Polyamide 12 as Polymer Matrix Nanocomposites", EGTRIB Journal, Vol. 14, No. 4, October 2017, pp. 40 - 53, (2017).

12. Hassan A. El-Sayed M., EiD A. I., El-Sheikh M., Ali W. Y., "Effect of Graphene Nanoplatelets and Paraffin Oil Addition on the Mechanical and Tribological Properties of 
Low Density Polyethylene Nanocomposites", Arabian Journal for Science and Engineering, November 2017, (2017).

13. Parikh H. H., "Experimental investigation and prediction of wear behavior of cotton fiber polyester composites", Friction Vol. 5 (2), June 2017, pp. 183 - 193, (2017).

14. Ferreira M. V. F., "Thermogravimetric characterization of polyester matrix composites reinforced with eucalyptus fibers", Volume 6, Issue 4, October-December 2017, pp. $396-400$, (2017).

15. Nirmal U., Hashim J., "Testing methods in tribology of polymeric composites", International Journal of Mechanical and Materials Engineering, (IJMME), Vol.6, No. 3, pp. 367 - 373, (2011).

16. Suresha B., Chandramohan G., "The Role of Fillers on Friction and Slide Wear Characteristics in Glass-Epoxy Composite Systems." Journal of Minerals \& Materials Characterization \& Engineering, Vol. 5, January 2009, pp 87 - 101, (2009).

17. Dammak M., Kharrat M., Smaoui I. and Rhaiem, S., "Effects of the test conditions on the friction and wear of polyethylene', Int. J. Microstructure and Materials Properties, Vol. 7, No. 5, pp. 400 - 416, (2012).

18. Basavarajappa S., "Effect of Filler Materials on Dry Sliding Wear Behavior of Polymer Matrix Composites - A Taguchi Approach." Journal of Minerals and Materials Characterization and Engineering, Vol. 8, No. 5, pp. 379 - 391, (2009).

19. Ameer A. K., Ali W. Y. and Elzayady N., "Friction and wear of Polymeric Composites Filled by oils", Journal of the Egyptian Society of Tribology, Vol. 17, No. 4, pp. 44 - 54, (2020).

20. Khashaba M. I., Youssef M. M., and Ali W. Y., "Adhesive Wear of Epoxy Filled by Oil, Metallic and Polymeric Powder", Bulletin of the Faculty of Engineering, Minia University, Vol. 20, No. 1., July 2001, pp. 1 - 10, (2001).

21. Dzhanakmedov A. H., and Pascoe M. W., "The Wear of Oil Filled Thermoplastic", Proceedings of the 3rd Leeds-Lyon Symposium on Tribology, The University of Leeds, England, Paper III (iii), pp. 60 - 64, (1976).

22. EL-Abden S. Z., Abo El-Wafa A., "Friction and Wear of Epoxy Flooring Filled by Recycled Polymers", International Journal of Scientific \& Engineering Research, Vol. 5, Issue 9, September-2014, pp. 116 - 121, (2014).

23. Khattab A. A. and Ali W. Y., "Abrasion Resistance of Recycled Polymeric Coatings", Journal of the Egyptian Society of Tribology, Vol. 7, No. 1, January 2010, pp. 14 - 25, (2010). 